\title{
Resist Patterning Characteristics using KrF Laser-ablation Process
}

\author{
Hiroshi Yamaoka ${ }^{1}$, Julius Joseph Santillan ${ }^{2 *}$, Nobutaka Uemori ${ }^{1}$, and Toshiro Itani $^{2}$ \\ ${ }^{1}$ Marubun Corp., 8-1 Nihonbashi, Odenmacho, Chuo-ku, Tokyo 103-8577, Japan \\ ${ }^{2}$ The Institute of Scientific and Industrial Research, Osaka University, \\ 8-1 Mihogaoka, Ibaraki, Osaka 567-0047, Japan \\ *julius.santillan@sanken.osaka-u.ac.jp
}

\begin{abstract}
The patterning characteristics of a variety of resist material platforms were investigated using a $\mathrm{KrF}$ laser ablation process. The results showed that a fullerene-based resist material with a 170-nm film thickness is capable of sub-micron resolution up to $0.8 \mu \mathrm{m} \mathrm{1:1} \mathrm{lines} \mathrm{and}$ spaces $(\mathrm{L} / \mathrm{S})$. Moreover, using a novolac-based resist material, the dependence of laser ablation patterning performance on the resist process conditions was determined. An increase in the total exposure energy (exposure energy per pass $\times$ total number of passes) is necessary as the film thickness increases. Moreover, using the same novolac-based resist material fixed at a $5-\mu \mathrm{m}$ film thickness, results suggested that exposure energy has a more significant impact on the effective formation of laser ablation patterns (compared to number of exposure passes). Finally, preliminary investigations using a metal resist (at a $90-\mathrm{nm}$ film thickness) resulted in

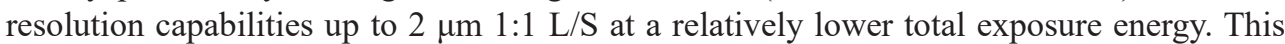
showed the potential of the metal resist material for application in laser ablation patterning. Keywords: KrF excimer laser, Laser-ablation patterning, Novolac, Fullerene, Metal resist
\end{abstract}

\section{Introduction}

The industrial application of excimer lasers for patterning miniature designs on substrates has and continues to be of great research interest [1-5]. Given the long history of laser technology, laser light is a very flexible tool for performing these tasks. One specific example is the effective scaling of semiconductor devices to nanometer levels [2,3, $5,7]$. Largely, this has been made possible through the application of shorter wavelength laser light sources $[2,3,5]$. However, with the complicated methods applied here, such technologies become inaccessible $[8,9]$, especially for purposes that do not really require stringent patterning targets.

Laser ablation is an application that allows micrometer scale patterning capability. The concept of laser ablation involves irradiating a material, allowing it to absorb a sufficient amount of photon energy, and causing significant heating, which subsequently vaporizes (into low molecular weight fragments) the irradiated area in the material $[10,11]$. This results in the formation of patterns (non- irradiated sections) in the material being processed.

Based on the same principle of achieving higher resolution patterns through wavelength reduction, the readily available krypton fluoride $(\mathrm{KrF})$ excimer laser with a wavelength $(\lambda)$ of $248 \mathrm{~nm}$ further extends the potential of laser ablation for patterning much smaller features.

In this paper, the patterning characteristics of a variety of resist material platforms were investigated using the $\mathrm{KrF}$ laser ablation process.

\section{Materials and processing}

\subsection{Materials}

Figure 1 shows the resist materials utilized for $\mathrm{KrF}$ laser ablation patterning: (a) novolac, (b) fullerene, and (c) siloxane resists. The novolac resist material was selected for its relatively high absorption at the wavelength of $248 \mathrm{~nm}[12,13]$. This property of high absorption is important to enable efficient ablation. The novolac resist used in these investigations possesses relatively high 


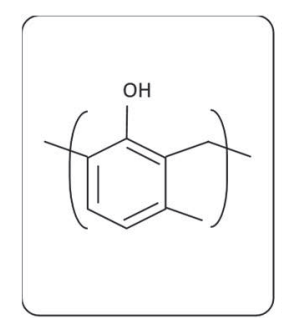

(a)

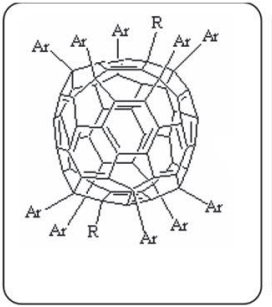

(b)

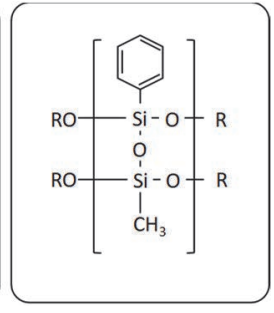

(c)

Fig. 1. Resist materials utilized for $\mathrm{KrF}$ laser-ablation patterning: (a) novolac, (b) fullerene, and (c) siloxane resists.

thermal stability. This property is also important in the laser ablation patterning process for preventing patterns from melting at the assumed high temperatures owing to the high energies absorbed by the film. Additionally, fullerene [14,15] and siloxane $[16,17]$ were also tested for this application, given their relatively high absorption properties at the wavelength of $248 \mathrm{~nm}$.

The resist materials were coated on $100-\mathrm{mm} \varphi$ wafers using a spin coater (IH-DXII by Mikasa) and baked at $100{ }^{\circ} \mathrm{C}$ in $120 \mathrm{~s}$ using a bake plate (EC7050 by AS-1). However, for the fullerene resist, the bake condition was $110^{\circ} \mathrm{C}$ for $60 \mathrm{~s}$. The resulting film thicknesses were measured using a spectroscopic measurement system (VM-1000 series by SCREEN). The novolac and siloxane resists were utilized at $1 \mu \mathrm{m}$, whereas the fullerene resist was applied at approximately $170 \mathrm{~nm}$. Additionally, the novolac resist was also prepared at 5 and $10 \mu \mathrm{m}$ to investigate the effect of the resist film thickness on the laser ablation patterning capability.

\subsection{Laser-ablation tool}

Figure 2 shows the $\operatorname{KrF}(\lambda=248 \mathrm{~nm})$ laser ablation tool in a (a) diagram and (b) photograph. As indicated in Table 1, the tool is equipped with a $\mathrm{KrF}$ laser as the light source with maximum

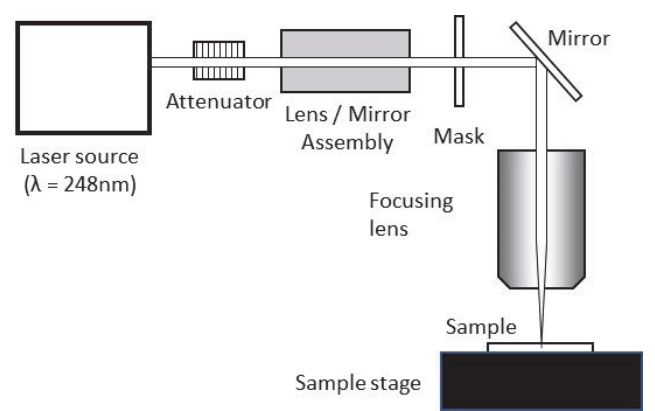

(a) specifications for stable power at $150 \mathrm{~W}$ and a pulse width of approximately $32 \mathrm{~ns}$.

To enable laser ablation patterning, the laser beam goes through a lens/mirror assembly and then a transparent mask designed with a number of pattern feature sizes.

The laser light then goes through a 0.13 numerical aperture (NA) telecentric lens, where a $5 \times$ reduction is performed before the laser light hits the resistcoated wafer placed on the XYZ $\Theta$ sample stage.

Table 1. KrF laser-ablation tool specifications.

\begin{tabular}{l|l}
\hline Parameter & Value / Comment \\
\hline Tool name & M3T (by Marubun) \\
Laser light source & LEAP150K (by Coherent) \\
Wavelength & $248 \mathrm{~nm}$ \\
Stable power $(\max )$ & $150 \mathrm{~W}$ \\
Repetition rate $(\max )$ & $150 \mathrm{~Hz}$ \\
Pulse width & $32 \pm 5 \mathrm{~ns}$ \\
Beam size $(\mathrm{V} \times \mathrm{H})$ & $32.5 \times 13 \mathrm{~mm}$ \\
NA & 0.13 \\
Maximum shot size & $18 \mathrm{~mm} \varphi$ \\
Sample stage resolution & $50 \mathrm{~nm}$ \\
Maximum sample size & $300 \times 300 \mathrm{~mm} \square$ \\
\hline
\end{tabular}

\section{Results and discussion}

3.1. Resist material type dependence

Figure 3 shows the optical microscope (measuring microscope MF by Mitutoyo) images of the $\mathrm{KrF}$ laser ablation patterns on the novolac, fullerene, and siloxane resist materials. The patterns formed with the novolac resist were obtained at an exposure energy of $400 \mathrm{~mJ}$ with five exposure passes. For the fullerene, the exposure conditions were $300 \mathrm{~mJ}$ in energy with three passes. The patterns obtained with siloxane were achieved at $300 \mathrm{~mJ}$ with 200 passes. These preliminary results showed that the novolac and fullerene resists exhibit resolutions of up to $1.2 \mu \mathrm{m} \mathrm{1:1} \mathrm{L/S}$. However, to better appreciate the pattern features, a more

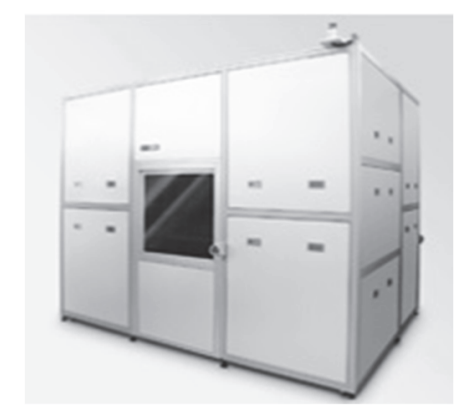

(b)

Fig. 2. KrF laser-ablation tool (a) schematic diagram and (b) photograph. 


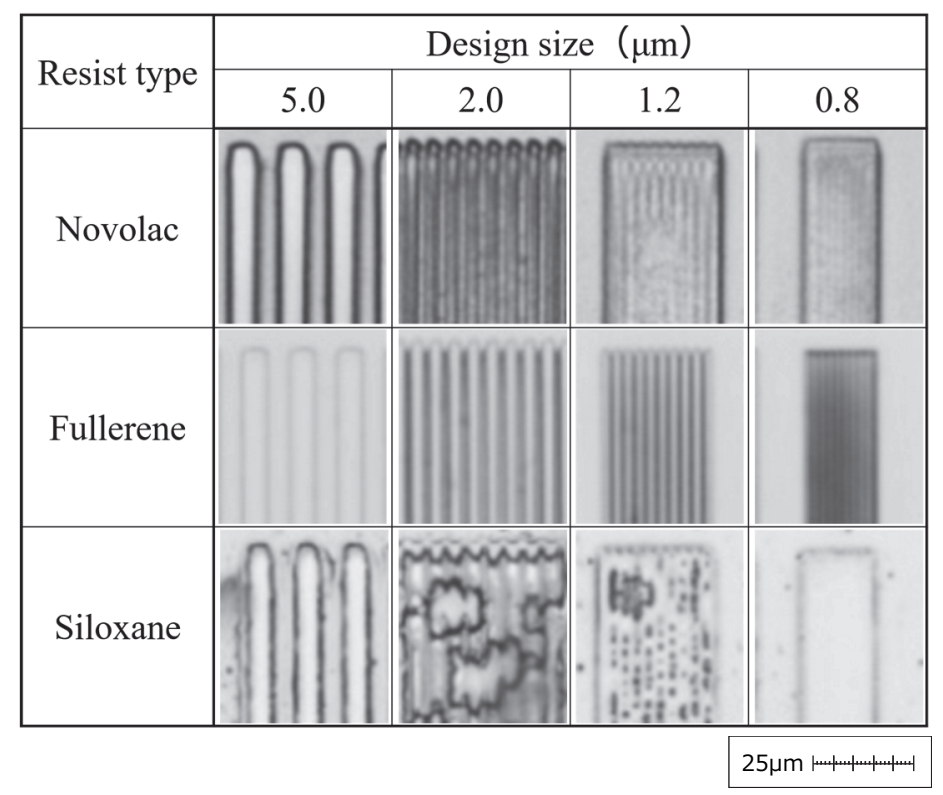

Fig. 3. Optical microscope images of laser-ablation patterns on various resist materials (at optimal exposure energy and pass conditions).

detailed analysis using a cross-sectional field emission scanning electron microscope (FE-SEM, S-4500 by Hitachi High-Technologies) was performed.

Figure 4 shows the cross-sectional SEM images of $\mathrm{KrF}$ laser ablation patterns on novolac, fullerene, and siloxane resists. From these results, it was found that the optimal exposure condition for novolac was $400 \mathrm{~mJ}$ with eight passes. For the fullerene, exposure conditions were found to be $300-\mathrm{mJ}$ energy with three passes. Whereas for patterns obtained with siloxane, the optimal exposure conditions were $400 \mathrm{~mJ}$ with 50 passes.

These results show that the actual resolution limit for novolac was $5 \mu \mathrm{m}$ 1:1 L/S with some pattern modulation at both 2 and $1.2 \mu \mathrm{m} \mathrm{1:1} \mathrm{L/S.} \mathrm{However,}$ at these resolution sizes, the pattern heights significantly decreased. For the fullerene resist, it is clear that the resolution at the sub-micron level is possible $(0.8 \mu \mathrm{m} 1: 1 \mathrm{~L} / \mathrm{S})$. Further investigations are being considered to better understand the mechanisms surrounding the patterning performance of the fullerene resist. For the siloxane resist, an ultimate resolution of $5 \mu \mathrm{m} \mathrm{1:1} \mathrm{L/S} \mathrm{was}$

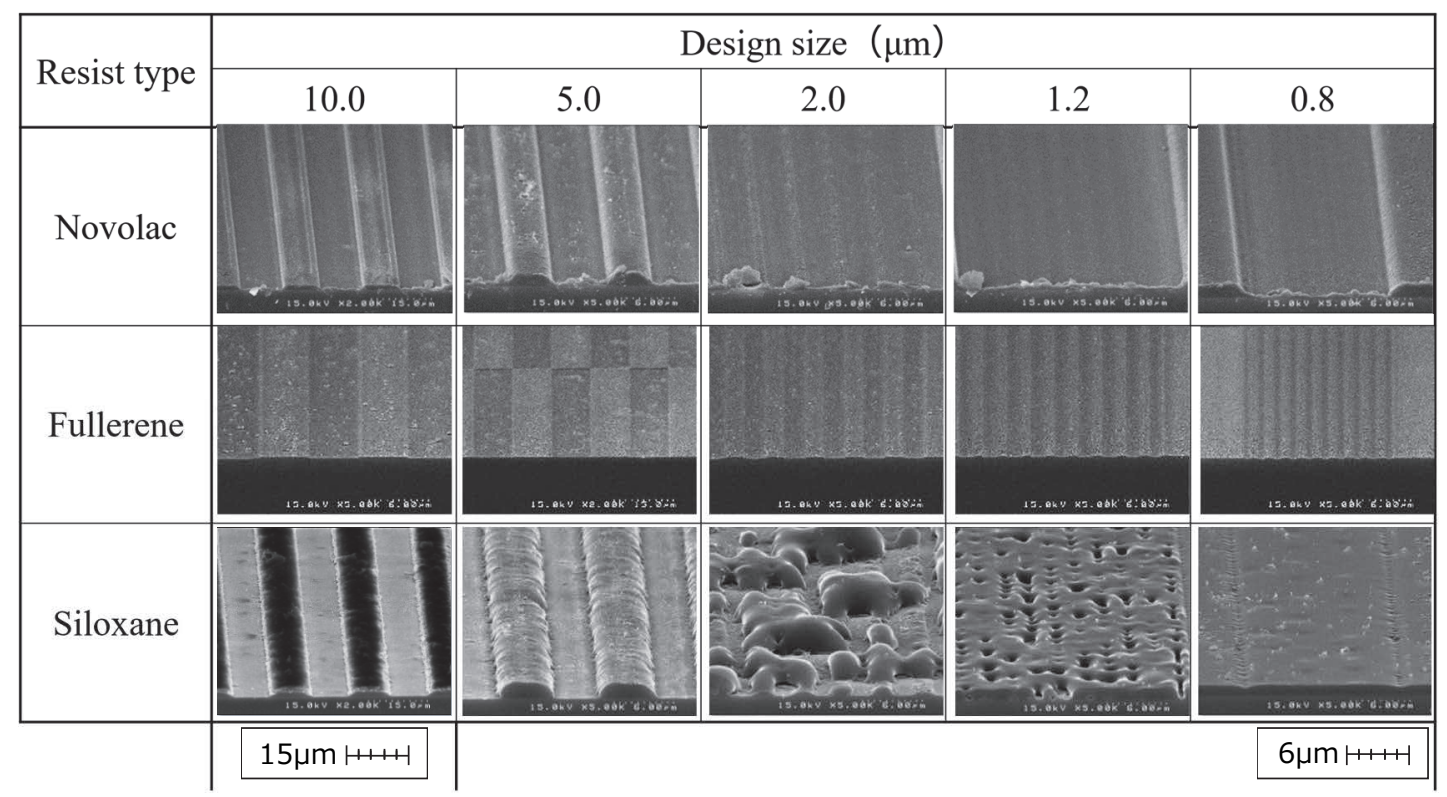

Fig. 4. Cross sectional SEM images of laser-ablation patterns on various resist materials (at optimal exposure energy and pass conditions). 
observed. However, the patterns were found to have very rough and bloated-like edges, suggesting that a melting mechanism may be occurring. This assumption is supported in the images found for the $2 \mu \mathrm{m} \mathrm{1:1} \mathrm{L/S} \mathrm{and} \mathrm{sizes} \mathrm{below} \mathrm{where} \mathrm{the} \mathrm{lines} \mathrm{have}$ been observed to meld.

\subsection{Resist process dependence}

\subsubsection{Film thickness dependence}

Figure 5 shows the cross-sectional SEM images of the $\mathrm{KrF}$ laser ablation patterns on the novolac resist at various film thicknesses of 1,5 , and $10 \mu \mathrm{m}$. Compared with the optimal exposure conditions for the $1-\mu \mathrm{m}$ film thickness ( $400 \mathrm{~mJ}$ at 8 passes), the exposure conditions for the 5 - and $10-\mu \mathrm{m}$ film thickness conditions increased at $800 \mathrm{~mJ}$ with 15 passes and $800 \mathrm{~mJ}$ with 30 passes, respectively. Ideal pattern shapes (relatively sharp cornered patterns) were obtained at the $5-\mu \mathrm{m}$ film thickness condition, where the potential for pattern resolution was observed to improve to $1.2 \mu \mathrm{m} 1: 1 \mathrm{~L} / \mathrm{S}$. However, upon closer inspection, the residual resist remained in the pattern spaces; thus, further material and process enhancements are assumed necessary. For the $10-\mu \mathrm{m}$ film thickness condition, the ultimate resolution was limited to $5 \mu \mathrm{m} 1: 1 \mathrm{~L} / \mathrm{S}$, as pattern sizes lower than this were found to have totally disappeared in the exposure conditions utilized.

\subsubsection{Exposure energy dependence}

Figure 6 shows the cross-sectional SEM images of $\mathrm{KrF}$ laser ablation patterns on the novolac resist (5- $\mu \mathrm{m}$ film thickness) at various exposure energies at a fixed exposure pass of 15 . Using these results, observation of the laser ablated patterns at various exposure energies shows how the resist film in the pattern spaces are etched away by the laser as higher energies are applied. Focusing on the $5 \mu \mathrm{m} 1: 1 \mathrm{~L} / \mathrm{S}$, it was observed that the mid-portion of the bottom section of the spaces was etched away faster than the sides closer to the bottom of the lines. However, this effect is minimized as higher energies are deposited, causing laser ablation to occur deeper into the resist film, eventually reaching the substrate (in this case, $\mathrm{Si}$ ) at the bottom. However, for pattern sizes below $2 \mu \mathrm{m} \mathrm{1:1} \mathrm{L/S,} \mathrm{an} \mathrm{obvious} \mathrm{film} \mathrm{thickness}$ loss simultaneously occurs as the bottom sections of the space area are etched away, limiting the resolution capability of the resist material.

\subsubsection{Exposure pass dependence}

Figure 7 shows the cross-sectional SEM images of $\mathrm{KrF}$ laser ablation patterns on the novolac resist (5- $\mu \mathrm{m}$ film thickness) with various exposure passes at a fixed exposure energy of $800 \mathrm{~mJ}$. Through these results, observation of the laser ablated patterns at various exposure passes shows how the resist film in the pattern spaces are etched away by the laser as more exposure passes of a fixed energy are applied.

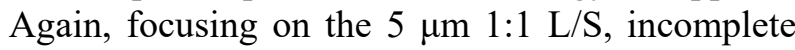
etching of the resist film was observed at passes 8 and 10 (similar to the effect of lower energies in the previous section). Compared to the ones described in 3.2.2, these results suggest that exposure energy has a more significant impact on the effective formation of patterns through laser ablation.

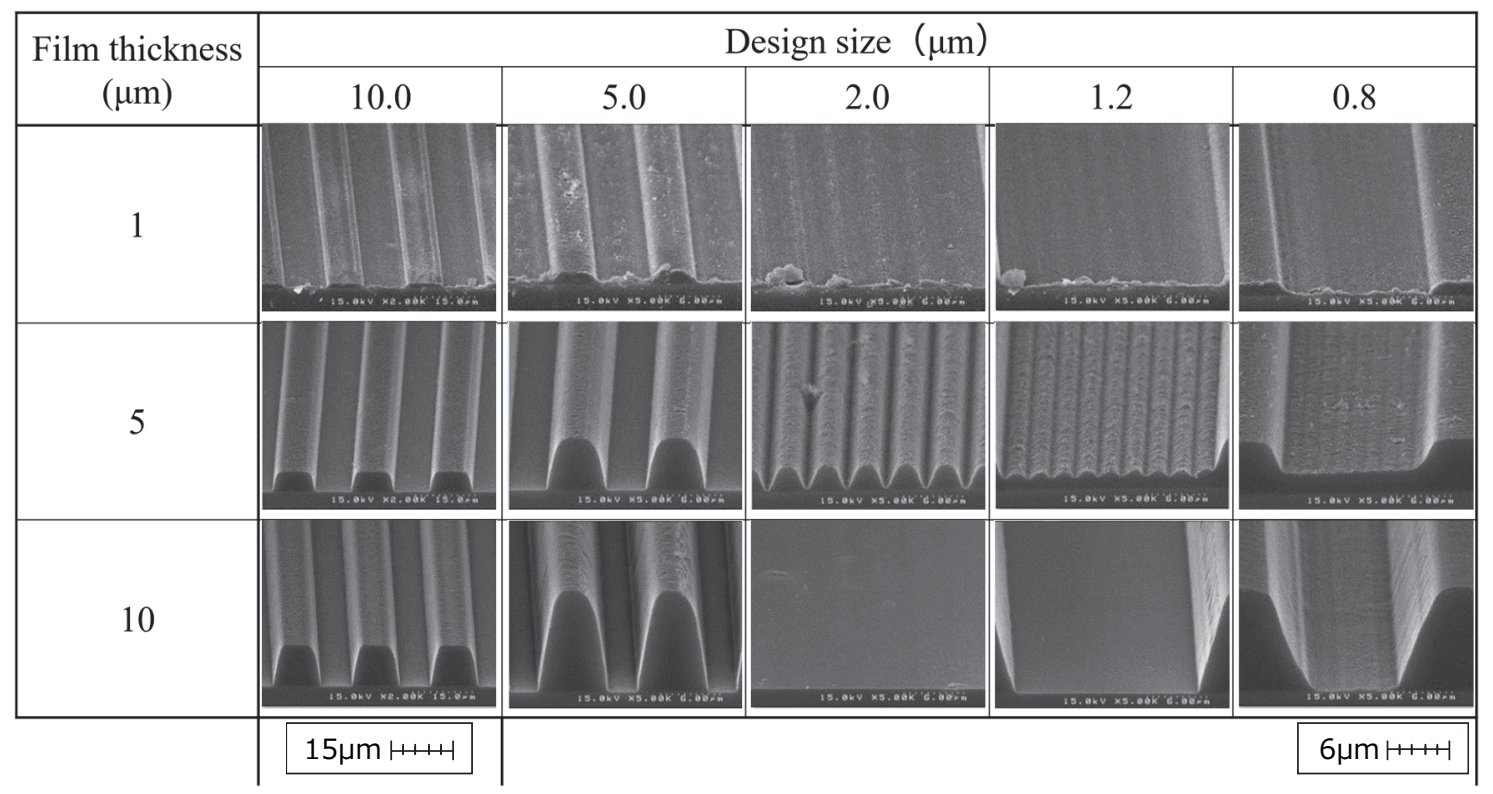

Fig. 5. Cross-sectional SEM images of laser-ablation patterns on the novolac resist at various film thicknesses (at optimal exposure energy and pass conditions). 


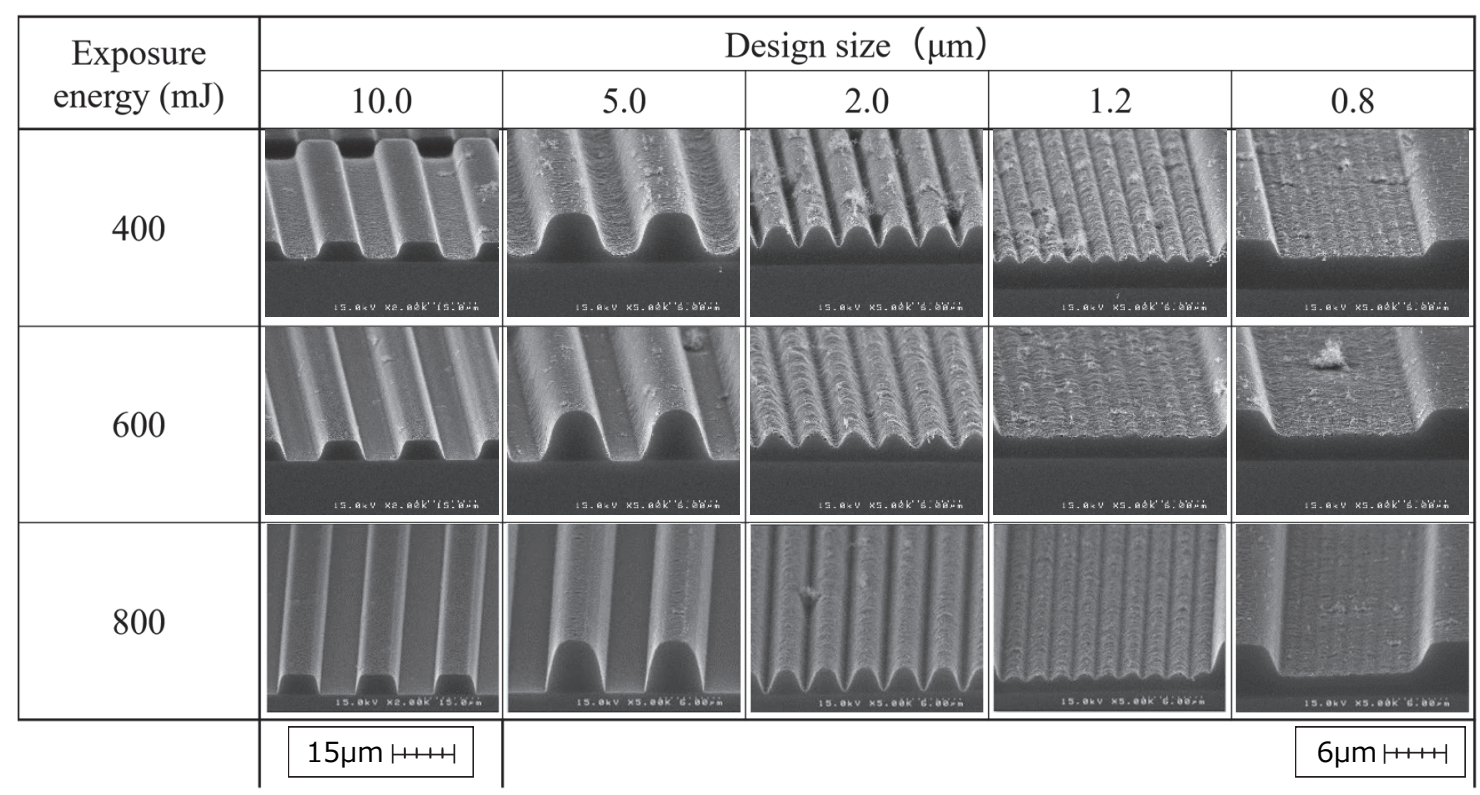

Fig. 6. Cross-sectional SEM images of laser-ablation patterns on the novolac resist (5- $\mu \mathrm{m}$ film thickness) at various exposure energies at a fixed exposure pass of 15 times.

\begin{tabular}{|c|c|c|c|c|c|}
\hline \multirow{2}{*}{$\begin{array}{c}\text { Exposure } \\
\text { pass (times) }\end{array}$} & \multicolumn{5}{|c|}{ Design size $(\mu \mathrm{m})$} \\
\hline & 10.0 & 5.0 & 2.0 & 1.2 & 0.8 \\
\hline \multicolumn{6}{|l|}{8} \\
\hline \multicolumn{6}{|l|}{10} \\
\hline \multicolumn{6}{|l|}{15} \\
\hline & $15 \mu \mathrm{m}$ & & & & $6 \mu \mathrm{m}$ \\
\hline
\end{tabular}

Fig. 7. Cross-sectional SEM images of laser-ablation patterns on the novolac resist (5- $\mu \mathrm{m}$ film thickness) at various exposure passes at a fixed exposure energy of $800 \mathrm{~mJ}$.

\subsection{Application of the metal resist}

The results obtained in Section 3.1 related to fullerene suggest that the resist film thickness may play a large role in achieving a higher resolution for $\mathrm{KrF}$ laser ablation patterning. However, considering future applications where the resist acts as a mask for etching the substrate (e.g. Si or $\mathrm{Cu}$ ), the etching resistance of the resist material to typical etching gases is an important factor. Fullerene has been reported to have a relatively higher etching resistance compared with typical chemically amplified resists [15].
Another material that is known to have superior etching resistance even at very thin film thickness applications is the "metal resist" [18-21]. This material is composed of a metal core surrounded by an organic shell. For these investigations, a metal resist using a $\mathrm{ZrOx}$ core and an organic shell was utilized. This metal resist was coated at $90 \mathrm{~nm}$ under baking conditions of $100{ }^{\circ} \mathrm{C}$ for $120 \mathrm{~s}$.

Figure 8 shows the optical microscope images of $\mathrm{KrF}$ laser ablation patterns on the metal resist. The exposure conditions (150-mJ energy and ten passes) were relatively lower compared with the previously described resist materials. This suggests that the 


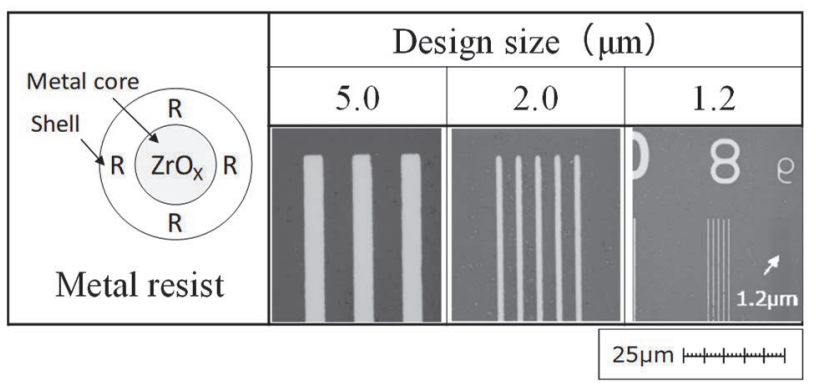

Fig. 8. Optical microscope images of $\mathrm{KrF}$ laserablation patterns on the metal resist (at optimal exposure energy and pass conditions).

metal resist effectively absorbs the $248 \mathrm{~nm}$ wavelength laser light, allowing for ease of laser ablation patterning. As the images show, the metal resist is capable of patterning at $2.0 \mu \mathrm{m} 1: 1 \mathrm{~L} / \mathrm{S}$, making it a potentially high-resolution resist for this type of patterning technology.

\section{Summary}

$\mathrm{KrF}$ laser ablation patterning can enable submicron patterning, depending on the resist platform and process conditions. Moreover, investigations on the dependence of laser ablation patterning on the resist process (i.e., film thickness) and exposure conditions (energy and pass) also show that further optimization of the patterning resolution/quality is possible.

Finally, preliminary investigations using a metal resist resulted in resolution capabilities up to $2 \mu \mathrm{m}$ $1: 1 \mathrm{~L} / \mathrm{S}$ at a relatively lower total exposure energy. This showed the potential of the metal resist material for application to laser ablation patterning.

\section{Acknowledgments}

We thank the material suppliers for the providing the resist materials and fruitful discussions for this work.

\section{References}

1. O. Wood II, J. Photopolym. Sci. Technol., 30 (2017) 599.

2. J. H. Bruning, Proc. SPIE, 6520 (2007) 652004.

3. M. Rothschild, Materialstoday, 8 (2005) 18.

4. S. Nakamura, K. Midorikawa, H. Kumagai, M. Obara, and K. Toyoda, Jpn. J. Appl. Phys., 35 (1996) 101.
5. B. J. Lin, J. Vac. Sci. Technol., 12 (1975) 1317.

6. Z. Tasdemir, X. Wang, I. Mochi, L. van LentProtasova, M. Meeuwissen, R. Custers, G. Rispens, R. Hoefnagels, and Y. Ekinci, Proc. SPIE, 10809 (2018) 108090L.

7. D. De Simone, P. Vanelderen, and G. Vandenberghe, J. Photopolym. Sci. Technol., 30 (2017) 613.

8. A. Wüest, A. J. Hazelton, and G. Hughes, Proc. SPIE, 7271 (2009) 72710Y.

9. W. Trybula and D. Dance, Proc. SPIE, 3048 (1997) 211.

10. C. Momma, B. N. Chichkov, S. Nolte, F. von Alvensleben, A. Tünnermann, H. Welling, and B. Wellegehausen, Opt. Commun., 129 (1996) 134.

11. M. Brown and C. Arnold, "Laser Precision Microfabrication", K. Sugioka, M. Meunier, A. Piqué, Eds., Springer, Berlin Heidelberg, 2010, p. 91.

12. G. Taylor, "Microelectronic Materials and Processes", R. Levy, Ed., Springer, Netherlands, 1989, p. 365.

13. H. Ito and C. G. Wilson, ACS Symp. Ser, 242 (1984) 11.

14. N. L. Dmitruk, O. Borkovskaya, S.V. Mamykin, D. O. Naumenko, N. I. Berezovska, I. M. Dmitruk, V. Meza-Laguna, E. Alvarez-Zauco, and E. V. Basiuk, J. Nanosci. Nanotechnol., 8 (2008) 1.

15. H. Oizumi, K. Matsumaro, J. J. Santillan, G. Shiraishi, K. Kaneyama, K. Matsunaga, and T. Itani, Proc. SPIE, 7639 (2010) 76390R.

16. H. Miyazoe, S. Engelmann, and M. Guillorn, D. Pei, W. Li, J. Lauer, and J. Shohet, J. Vac. Sci. Technol. A, 35 (2017) 05C306.

17. D. R. McKean, N. J. Clecak, and L. A. Pedersen, Proc. SPIE, 1262 (1990) 110.

18. R. Brainard, Proc. SPIE, 10960 (2019) 1096002.

19. C. Ober, H. Xu, V. Kosma, K. Sakai, and E. P. Giannelis, Proc. SPIE, 10583 (2018) 1058306.

20. M. Toriumi, Y. Sato, M. Koshino, K. Suenaga and T. Itani, Appl. Phys. Express, 9 (2016) 031601.

21. T. Fujimori, T. Tsuchihashi, S. Minegishi, T. Kamizono, and T. Itani, Proc. SPIE, 9776 (2016) 977605. 